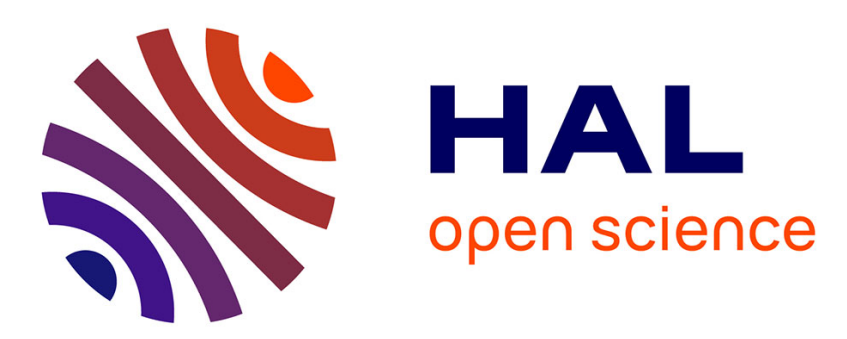

\title{
Ultrasound propagation in amorphous polystyrene at low temperature
}

Jean Yves Duquesne, G. Bellessa

\section{To cite this version:}

Jean Yves Duquesne, G. Bellessa. Ultrasound propagation in amorphous polystyrene at low temperature. Journal de Physique Lettres, 1979, 40 (8), pp.193-195. 10.1051/jphyslet:01979004008019300 . jpa-00231605

\section{HAL Id: jpa-00231605 https://hal.science/jpa-00231605}

Submitted on 1 Jan 1979

HAL is a multi-disciplinary open access archive for the deposit and dissemination of scientific research documents, whether they are published or not. The documents may come from teaching and research institutions in France or abroad, or from public or private research centers.
L'archive ouverte pluridisciplinaire HAL, est destinée au dépôt et à la diffusion de documents scientifiques de niveau recherche, publiés ou non, émanant des établissements d'enseignement et de recherche français ou étrangers, des laboratoires publics ou privés. 


\title{
Ultrasound propagation in amorphous polystyrene at low temperature
}

\author{
J.-Y. Duquesne and G. Bellessa \\ Laboratoire de Physique des Solides $\left({ }^{*}\right)$, \\ Université Paris-Sud, 91405 Orsay, France \\ (Reçu le 6 février 1979, révisé le 2 mars 1979, accepté le 5 mars 1979)
}

Résumé. - Des mesures de l'atténuation acoustique et de la vitesse du son dans le polystyrène amorphe jusqu'à $0,37 \mathrm{~K}$ sont présentées. Le domaine de fréquences est 15-190 MHz. Aux plus basses températures, la vitesse suit la loi logarithmique particulière des matériaux amorphes mais l'atténuation ne révèle pas la loi attendue.

\begin{abstract}
Measurements of the acoustical attenuation and sound velocity in amorphous polystyrene down to $0.37 \mathrm{~K}$ are reported. The frequency range is from 15 to $190 \mathrm{MHz}$. At the lowest temperatures, the velocity exhibits the logarithmic temperature dependence usual in amorphous materials, but the attenuation does not reveal the expected law.
\end{abstract}

The acoustical properties at low temperature of amorphous materials are very different from those of crystals. These properties have been extensively studied in covalent glasses and in metals. In polymers below $1 \mathrm{~K}$ there is only, to our knowledge, one study of the acoustical properties which has been made in amorphous selenium [1]. So it is interesting to study a classical organic polymer, such as polystyrene, in order to establish the generality of the acoustical laws in these materials at low temperature and to compare the experimental results with those obtained in covalent glasses and amorphous metals. In this letter we report measurements of the acoustic attenuation and the sound velocity down to $0.37 \mathrm{~K}$ in some amorphous polystyrene samples of different molecular weights.

Three samples (here after called 1, 2, 3) have been made with commercial polystyrene having 3 different average molecular weights which are 22000 , 321000 and 2000000 respectively. The sound velocity variations are reported in figure 1 and figure 2 . The measurements are made with a phase comparison method, which allows only measurements of relative variations but with a good accuracy. The velocity which is taken as a reference in figure 1 is the velocity at $0.37 \mathrm{~K}$ (the lowest attainable temperature of our apparatus). It appears in figure 1 that the velocity increases with increasing temperature up to $0.9 \mathrm{~K}$, following a logarithmic law at the lowest temperatures.

(*) Associé au Centre National de la Recherche Scientifique.

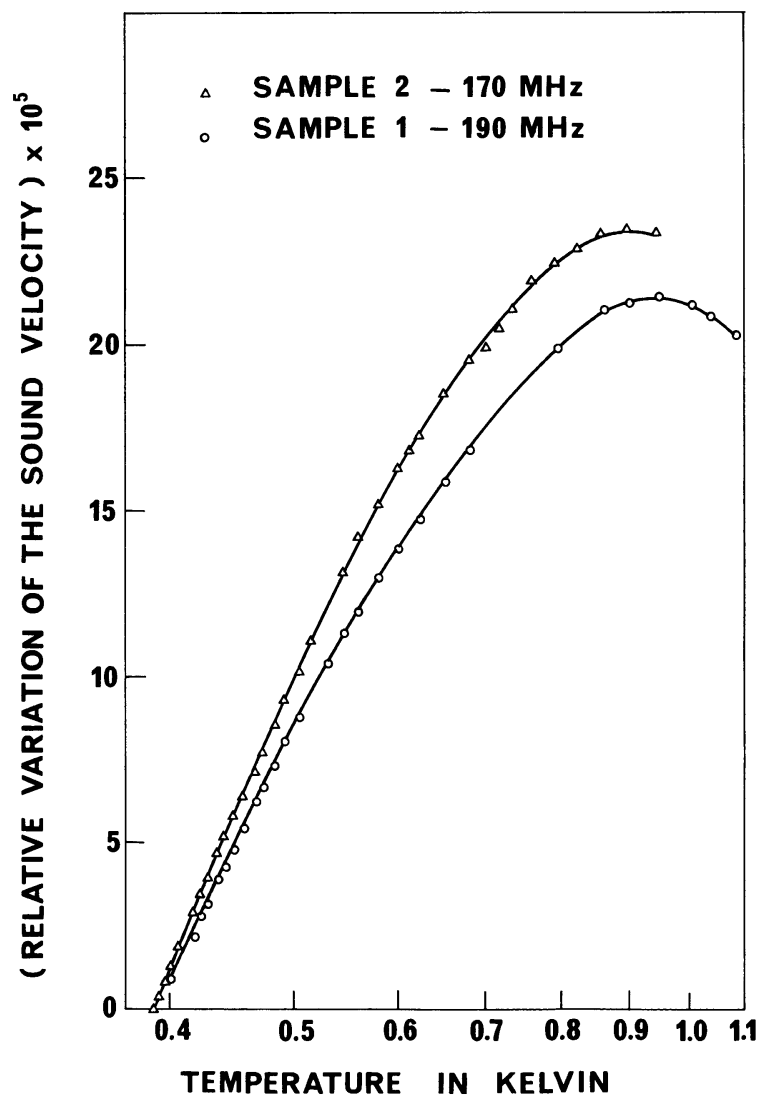

Fig. 1. - Relative variation of the velocity of longitudinal sound waves as a function of temperature in amorphous polystyrene. The velocity variation is relative to the value at $0.37 \mathrm{~K}$. The longitudinal wave velocity is $2.8 \times 10^{5} \mathrm{~cm} / \mathrm{s}$. Samples 1 and 2 have an average molecular weight of 22000 and 321000 respectively. 


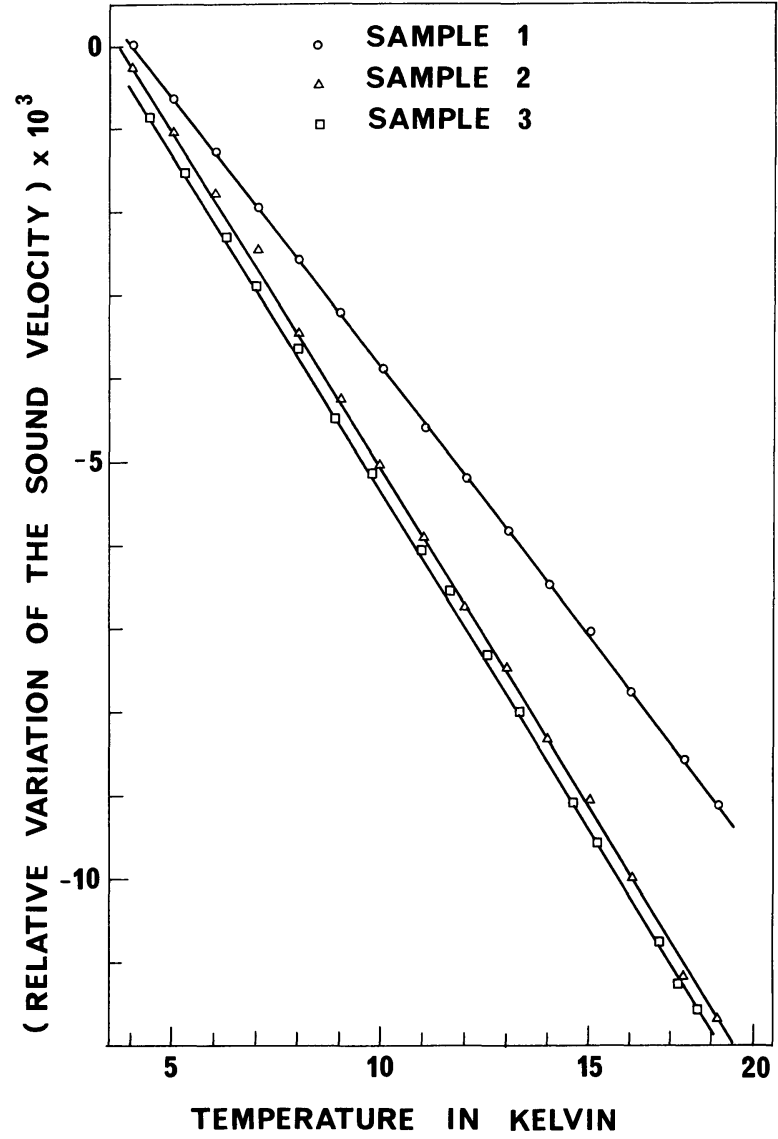

Fig. 2. - Relative variation of the velocity of longitudinal sound waves as a function of temperature in amorphous polystyrene. Samples 1, 2 and 3 have an average molecular weight of 22000 , 321000 and 2000000 respectively.

Then it decreases linearly with increasing temperature (Fig. 2). These results are very similar to those obtained in selenium [1]. For the sake of clarity, we have not reported in figure 1 the results at low frequencies. As the frequency is lowered, the temperature of the velocity maximum decreases and at $50 \mathrm{MHz}$ it is around $0.6 \mathrm{~K}$ as in selenium for the same frequency [1]. In covalent glasses [2] and in amorphous metals [3] the velocity maximum is located at higher temperatures. Between sample 1 (average M.W. 22000 ) and sample 2 (average M.W. 321000 ) there is a difference of the slope at low temperature of about $10 \%$. Sample 3 (average M.W. 2000000 ) has also been studied, but only at $50 \mathrm{MHz}$. It has not been possible to study this sample at higher frequencies due to a large attenuation background and at $50 \mathrm{MHz}$ the lowest attainable temperature of our apparatus is not sufficiently low to obtain the logarithmic temperature law with good accuracy. At higher temperatures (Fig. 2), we find for the three samples a velocity decrease which is proportional to the temperature as usual [4]. Samples 2 and 3 give the same slope and sample 1 gives a slope $20 \%$ smaller than the others (Fig. 2). The acoustic attenuation has been also measured for different frequencies. The results are

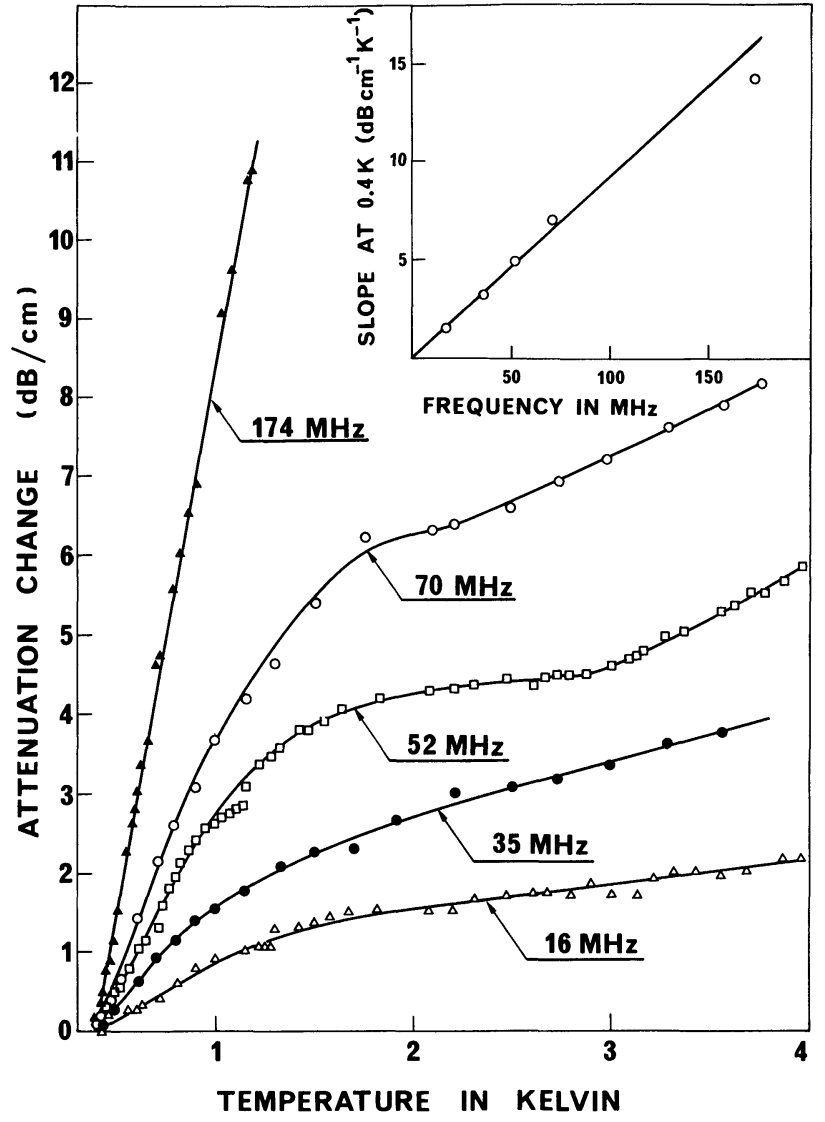

Fig. 3. - Attenuation of longitudinal sound waves as a function of temperature in amorphous polystyrene for various frequencies. The inset shows the frequency dependence of the slope of the attenuation at the lowest temperatures.

very similar for the three samples. Those for sample 2 are reported in figure 3. As in selenium, there is at $50 \mathrm{MHz}$ a small attenuation peak around $1.5 \mathrm{~K}$ which seems to be displaced toward higher temperatures as the frequency is increased. A similar peak exists in covalent glasses around $5 \mathrm{~K}$ [5]. At the lowest temperatures, the attenuation is proportional to the temperature (Fig. 3) and also proportional to the frequency (inset of Fig. 3). In polymethylmethacrylate (PMMA) a linear temperature dependence of the acoustic attenuation has also been observed above $1 \mathrm{~K}$ at $18 \mathrm{GHz}$ [6].

The behaviour of the sound velocity at the lowest temperatures is well explained with the model proposed by Anderson et al. [7] and Phillips [8]. This model assumes the existence of two-level systems. At low temperature, there is a resonant interaction between the ultrasonic wave and the two-level systems. This interaction leads to an increase of the velocity as the temperature is increased. The velocity variation is given by [2]

$$
\frac{V(T)-V\left(T_{0}\right)}{V\left(T_{0}\right)}=\frac{n_{0} M^{2}}{\rho V^{2}} \ln \frac{T}{T_{0}}
$$


where $n_{0}$ is the two-level system density of states, $M$ the coupling constant between the two-level systems and the ultrasonic wave, $\rho$ the specific mass and $T_{0}$ an arbitrary reference temperature. Eq. (1) is valid for low frequency sound waves ( $\hbar \omega \ll k_{\mathrm{B}} T$ where $\omega$ is the angular frequency). Fitting our experimental results (Fig. 1) with eq. (1) and using $\rho=1.05 \mathrm{~g} / \mathrm{cm}^{3}$ and $V_{1}=2.8 \times 10^{5} \mathrm{~cm} / \mathrm{s}$, we obtain for samples 1 and 2 respectively

$$
\begin{aligned}
& n_{0} M_{1}^{2}=3 \times 10^{7} \mathrm{erg} / \mathrm{cm}^{3} \\
& n_{0} M_{1}^{2}=3.4 \times 10^{7} \mathrm{erg} / \mathrm{cm}^{3} .
\end{aligned}
$$

The difference between these two values is not significant because it can be due to a sound velocity difference within a few percent. It is interesting to compare these values with the coupling parameter in selenium [1]. There is, however, a problem because the coupling parameter in selenium is known only for transverse waves $\left(n_{0} M_{\mathrm{t}}^{2}=0.5 \times 10^{7} \cdot \mathrm{erg} / \mathrm{cm}^{3}\right)$ and the present study is made with longitudinal waves. Nevertheless the coupling parameter is always larger for longitudinal waves than for shear waves : there is a factor of about 2 in metals [3] and a factor of 4 in covalent glasses [5]. Hence, the coupling parameter for longitudinal waves in selenium would be from 1 to $2 \times 10^{7} \mathrm{erg} / \mathrm{cm}^{3}$, which is close to the values obtained in polystyrene. It may be remarked that the coupling parameter in these materials is one order of magnitude smaller than those in covalent glasses [5] and of the same order of magnitude as those in amorphous metals [3]. Furthermore, it is interesting to deduce from our measurements the value of the coupling parameter $M_{1}$ taking into account the specific heat measurements below $1 \mathrm{~K}$ in polystyrene [9]. These measurements lead to

$$
n_{0}=1.6 \times 10^{33} \mathrm{erg}^{-1} \mathrm{~cm}^{-1} \text {. }
$$

Hence we obtain $M_{1}=0.09 \mathrm{eV}$ which is to be compared with the value $M_{1}=0.3 \mathrm{eV}$ in $\mathrm{SiO}_{2}$ [2].

The coupling of the ultrasonic beam with the twolevel systems leads to two different attenuation processes. The first one is a resonant interaction between the acoustic wave and the two-level systems which have the same splitting energy as the phonon energy. This process leads to an attenuation inversely pro- portional to the temperature [10]. However, it is necessary to reach lower temperatures (or higher frequencies) than those used in the present work in order to observe this attenuation law [5]. The second attenuation process appears at higher temperatures. It is the relaxation towards the thermal equilibrium of the whole of the two-level systems which is disturbed by the ultrasonic wave. This process leads to an acoustic attenuation which is proportional to $T^{3}$ and is frequency independent in the limiting case of high frequency or low temperature $\left(\omega \tau_{m} \gg 1\right)$. In the limiting case of low frequency or high temperature $\left(\omega \tau_{\mathrm{m}} \gg 1\right)$, the attenuation is proportional to the frequency and temperature independent [10]. The $T^{3}$ law has been observed in glasses above $0.3 \mathrm{~K}$ and around $100 \mathrm{MHz}[11,12]$. In polystyrene, we do not observe this law. At the lowest temperatures, the attenuation is proportional to the temperature (Fig. 3) and to the frequency (inset of figure 3). Between $0.37 \mathrm{~K}$ and $0.9 \mathrm{~K}$ our experimental results fit well with an attenuation law of the form

$$
\Gamma=\Gamma_{0}+K \omega T
$$

with $K=1.2 \times 10^{-7} \mathrm{~cm}^{-1} \mathrm{~K}^{-1} \mathrm{rad}^{-1} \mathrm{~s}^{-1}$. In amorphous metals such a law has also been observed but it has not been explained [13]. Nevertheless, the fact that we have not observed the $T^{3}$ law does not mean that it does not exist in polymers. Perhaps, even at $0.37 \mathrm{~K}$ the limiting case of low temperature $\left(\omega \tau_{\mathrm{m}} \gg 1\right)$ is not reached and it is necessary to work at still lower temperature in order to reveal the $T^{3}$ law.

From the study of the acoustical properties of amorphous polystyrene at low temperature, it may be concluded that polymers behave at low temperature like the other amorphous materials (glasses and metals). However, a singularity which seems common to polymers (at least polystyrene and selenium) is that relaxation appears at temperatures lower than those in glasses or amorphous metals. It appears also that the coupling parameter $n_{0} M^{2}$ which is obtained from the acoustic experiments does not depend on the details of the structure but only on the type of the material : covalent glass, metal or polymer.

The authors are grateful to L. Liébert and C. Germain for fruitful discussions.

\section{References}

[1] Bellessa, G., Lemercier, C. and Caldemaison, D., Phys. Lett. 62A (1977) 127.

[2] Piché, L., Maynard, R., Hunklinger, S. and JäCKLe, J., Phys. Rev. Lett. 32 (1974) 1426.

[3] Bellessa, G., Doussineau, P. and Levelut, A., J. Physique Lett. 38 (1977) L-65.

Bellessa, G. and Bethoux, O., Phys. Lett. 62A (1977) 125.

[4] Bellessa, G., Phys. Rev. Lett. 40 (1978) 1456.

[5] Hunklinger, S. and Arnold, W., Physical Acoustics, edited by W. P. Mason and R. N. Thurston (Academic, New York) 1976, Vol. XII.

[6] Pelous, J. and Vacher, R., J. Physique 38 (1977) 1153.
[7] Anderson, P. W., Halperin, B. I. and Varma, C., Philos. Mag. 25 (1972) 1.

[8] Phillips, W. A., J. Low Temp. Phys. 7 (1972) 351.

[9] Stephens, R. B., Phys. Rev. B 8 (1973) 2896.

[10] JÄCKLE, J., Z. Phys. 257 (1972) 212.

[11] Hunklinger, S., Piché, L., Lasjaunias, J. C. and DransFelD, K., J. Phys. C : Solid State Phys. 8 (1975) 423.

[12] Jäckle, J., Piché, L., Arnold, W. and Hunklinger, S., J. Non-Cryst. Solids 20 (1976) 365.

[13] Doussineau, P., Levelut, A., Bellessa, G. and Bethoux, O., J. Physique Lett. 38 (1977) L-483. 